\title{
Magnetic Investigation of Carbon Coated Co-, Ni- and Fe-Nanoparticles
}

\author{
M. Makarewicz ${ }^{a}$, M. Podsiadey ${ }^{b}$ And M. Balanda ${ }^{a}$ \\ ${ }^{a}$ Henryk Niewodniczański Institute of Nuclear Physics \\ Polish Academy of Sciences \\ Radzikowskiego 152, 31-342 Kraków, Poland \\ ${ }^{b}$ Institute of Chemical and Environment Engineering \\ Szczecin University of Technology \\ Pułaskiego 10, 70-322 Szczecin, Poland
}

\begin{abstract}
Carbon coated cobalt-, nickel- and iron-nanoparticles were prepared by chemical method and their structural and magnetic properties were investigated. The samples were synthesized by carburization of the nanocrystalline form of the appropriate metal in $\mathrm{CH}_{4}$, followed up by the reduction of the obtained carbon deposits. The X-ray diffraction and transmission electron microscopy study revealed carbon coated Co-, Ni- and Fe-nanocapsules of the mean size $c a .50 \mathrm{~nm}$, and a small amount of carbon nanotubes. The measurements of magnetization and AC susceptibility were carried out for samples with different carbon content. A special attention was paid to the low temperature magnetic behavior. Decrease in the saturation moment at $T=4.2 \mathrm{~K}$ due to the nanosize of the particles was stronger for the samples with higher carbon content, while the coercivity field (610 Oe, 330 Oe and 390 Oe, for Co-, Ni-, and Fe-particles, respectively) was independent of carbon content. From the temperature dependence of $\mathrm{AC}$ and $\mathrm{DC}$ susceptibility a wide size distribution of the particles and blocking temperature above room temperature could be expected.
\end{abstract}

PACS numbers: 75.75.+a, 75.50.Tt

\section{Introduction}

Nanomagnetic materials are of great interest to physicists, chemists and material scientists alike. Manipulation of size for altering the physical properties of a material is a hot area of research not only from a fundamental point of view but also for potential applications. Magnetic nanoparticles are used for development of magnetic recording, magnetic fluids, catalysts, and in biomedicine. The important point of applications is the encapsulation of the magnetic material, in order to make it biocompatible and resistant to diverse environment. Among various types of magnetic nanocapsules [1], the ones built of a $3 d$ metal core and a graphite-like shell are in the center of interest $[2,3]$ because carbon is biocompatible, offers a large adsorption surface and provides an effective oxidation barrier.

In the present work, the nanoparticles of iron, cobalt and nickel coated with carbon were prepared by chemical method and their structural and magnetic properties were investigated. Properties of samples with different carbon content (CC) were compared and a special attention was paid to the low temperature magnetic behavior.

\section{Samples preparation}

The carbon coated Co-, Ni-, and Fe-nanoparticles $(\mathrm{Co}(\mathrm{C}), \mathrm{Ni}(\mathrm{C})$ and $\mathrm{Fe}(\mathrm{C}))$ were prepared in the five-step process: first, the nanocrystalline form of the appropriate metal was obtained by means of a cobalt, iron or nickel hydroxide precipitation, followed by calcination and reduction. A small amount of structural promoters (Ca and $\left.\mathrm{Al}_{2} \mathrm{O}_{3}\right)$ was added to stabilize the nanocrystalline metal structure at elevated temperatures. The mixture of metal hydroxides was calcined at $500^{\circ} \mathrm{C}$ and then reduced in $\mathrm{H}_{2}$ atmosphere in the temperature range $25-500^{\circ} \mathrm{C}$. The process of cobalt, nickel, and iron oxide reduction and metals carburization was carried out in differential reactor with thermogravimetric mass measurement [4]. Then, carburization in $\mathrm{CH}_{4}$ atmosphere at $500^{\circ} \mathrm{C}$ and reduction of carbon deposit was performed to obtain $\mathrm{Co}(\mathrm{C}), \mathrm{Ni}(\mathrm{C})$ and $\mathrm{Fe}(\mathrm{C})$ nanocapsules. After carburization the samples were cooled in helium atmosphere or were reduced in hydrogen atmosphere in the temperature range of 440$500^{\circ} \mathrm{C}$. Obtained samples contained different amount of promoters: $\mathrm{P}_{\mathrm{Co}}-0.2 \% \mathrm{CaO}, 1.5 \% \mathrm{Al}_{2} \mathrm{O}_{3}, \mathrm{P}_{\mathrm{Ni}}-0.8 \%$ $\mathrm{CaO}, 3.6 \% \mathrm{Al}_{2} \mathrm{O}_{3}$, and $\mathrm{P}_{\mathrm{Fe}}-1.1 \% \mathrm{CaO}, 2.1 \% \mathrm{Al}_{2} \mathrm{O}_{3}$.

\section{Structural characterization}

Transmission-electron microscope (TEM) images of metal samples carburized in methane $\left(\mathrm{CH}_{4}\right)$ atmosphere are presented in Fig. 1. The micrographs show the presence of carbon-encapsulated metal nanoparticles in all samples. The $\mathrm{Co}(\mathrm{C}), \mathrm{Ni}(\mathrm{C})$ and $\mathrm{Fe}(\mathrm{C})$ nanoparticles are composed of a metallic core and a carbon shell. The images obtained at larger magnification (Fig. 1B, D) reveal 


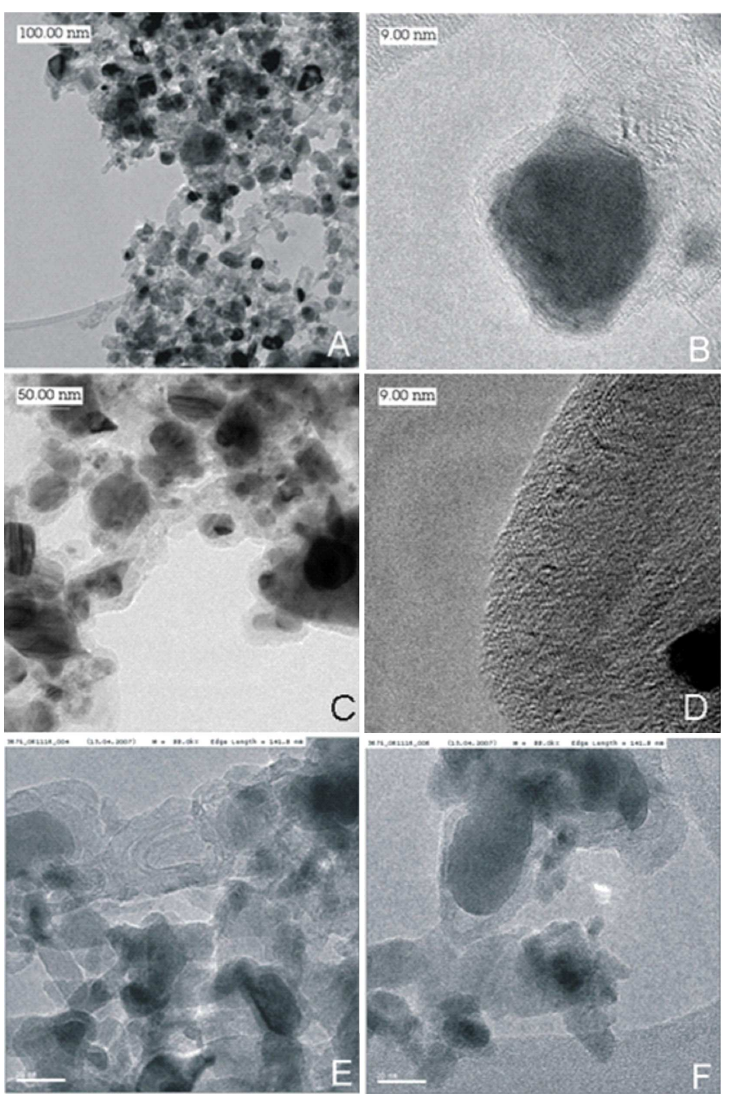

Fig. 1. TEM and HRTEM images of nickel (A)-(B), cobalt (C)-(D) and iron (E)-(F) samples after carburization in methane.

the layered structure of the crystalline graphite coating of some nanocapsules. Using the scale of the high-resolution TEM (HRTEM) magnification one may estimate the interplanar distance between two adjacent graphene planes which is about $0.340 \mathrm{~nm}$, close to the (002) lattice distance in graphite $(0.335 \mathrm{~nm})$. The thickness of coating depends on a metal used as a catalyst and is about $10 \mathrm{~nm}$ in case of cobalt and about $5 \mathrm{~nm}$ in case of iron and nickel particles.

The X-ray diffraction (XRD) patterns of samples after hydrogenation, recorded with $\mathrm{Cu} K_{\alpha}$ radiation, are presented in Fig. 2. For all samples the peaks attributed to the appropriate metal are clearly visible. The XRD pattern for $\mathrm{Co}(\mathrm{C})$ (Fig. 2A) indicates the existence of the face-centered cubic (fcc) and hexagonal closed-packed (hcp) phases. It is known $[4,5]$ that the fcc structure for pure cobalt exists only above $422^{\circ} \mathrm{C}$ and this form is not stable at room temperature. It appears that structural promoters added to stabilize the nanocrystalline metal structure have led to the formation of the fcc phase in our samples. The amount of carbon in all samples is very small and a peak attributed to graphite at $2 \theta \approx 26^{\circ}$ is not visible or has a very low intensity (Fig. $2 \mathrm{~B})$. In the XRD patterns of $\mathrm{Co}(\mathrm{C})$ and $\mathrm{Ni}(\mathrm{C})$ (Fig. 2A, B) the low intensity peaks characteristic of $\mathrm{Co}_{3} \mathrm{O}_{4}$ and $\mathrm{NiO}$ are present.

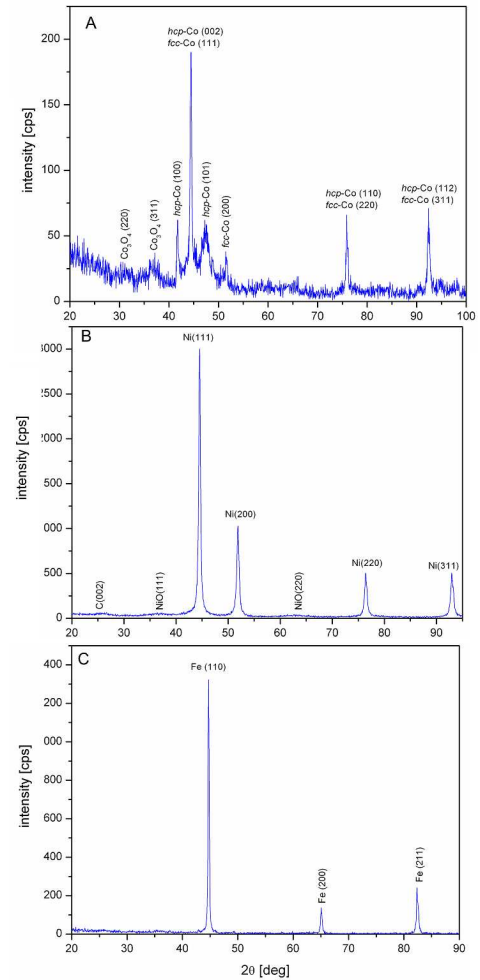

Fig. 2. The XRD patterns of (A) $\mathrm{Co}(\mathrm{C})$ sample after hydrogenation at $440^{\circ} \mathrm{C},(\mathrm{B}) \mathrm{Ni}(\mathrm{C})$ sample after hydrogenation at $560^{\circ} \mathrm{C},(\mathrm{C}) \mathrm{Fe}(\mathrm{C})$ sample after hydrogenation at $475^{\circ} \mathrm{C}$.

It suggests that some amount of non-encapsulated metal particles is present in the samples. These particles are not protected against the environmental degradation and in contact with air they become partially oxidized.

\section{Magnetic measurements}

Magnetic measurements were performed at Lake Shore 7225 AC susceptometer/DC magnetometer. The temperature dependence of static susceptibility $\chi_{\mathrm{DC}}$ in the range of 4.3-300 $\mathrm{K}$ was measured in the field $2 \mathrm{kOe}$. The magnetization curves and hysteresis loops were obtained at liquid helium temperature. AC susceptibility was measured with the frequency $f=125 \mathrm{~Hz}$ and the amplitude of the oscillating field of $H_{\mathrm{AC}}=1$ Oe and 5 Oe. Both real (in-phase) $\chi^{\prime}$ and imaginary (out-of-phase) $\chi^{\prime \prime}$ components were detected.

Figure 3 shows the hysteresis loops measured for examined samples at liquid helium temperature. Results for the $\mathrm{Co}(\mathrm{C}), \mathrm{Ni}(\mathrm{C})$ and $\mathrm{Fe}(\mathrm{C})$ nanocapsules with two different carbon contents are compared. The coercivity field equal to 610 Oe for $\mathrm{Co}(\mathrm{C}), 330$ Oe for $\mathrm{Ni}(\mathrm{C})$ and 390 Oe for $\mathrm{Fe}(\mathrm{C})$, was independent of $\mathrm{CC}$. The largest value of coercivity field for $\mathrm{Co}(\mathrm{C})$ particles may be related to the strong magnetocrystalline anisotropy of cobalt as compared to that of iron and nickel. In order to check whether we deal with magnetically isolated or interacting 


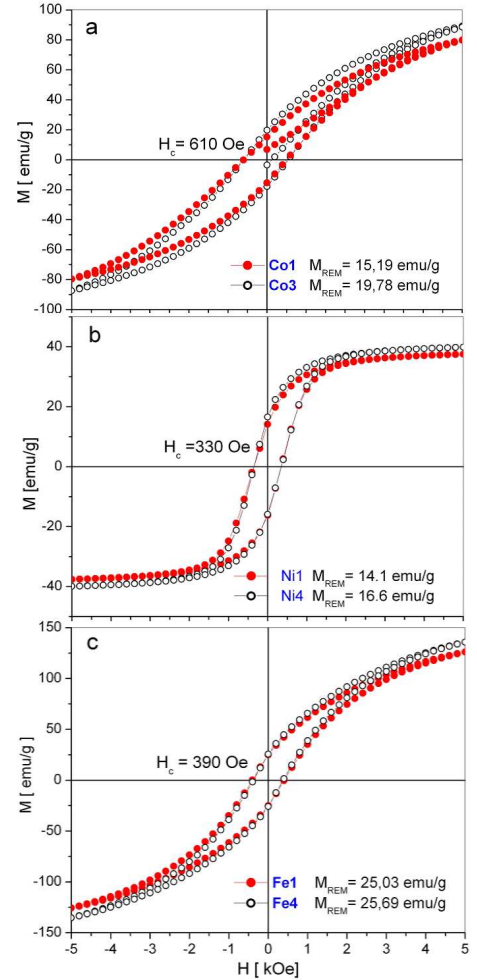

Fig. 3. Hysteresis loops measured at $T=4.3 \mathrm{~K}$ for (a) $\mathrm{Co}(\mathrm{C}),(\mathrm{b}) \mathrm{Ni}(\mathrm{C}),(\mathrm{c}) \mathrm{Fe}(\mathrm{C})$ samples with different carbon content.

particles, for $\mathrm{Ni}(\mathrm{C})$ capsules we have measured also hysteresis loops for sample cooled in the DC field of $10 \mathrm{kOe}$ and $30 \mathrm{kOe}$ (not shown). The weak shift of hysteresis loop by only 20 Oe showed that the bias coupling in the system is practically negligible and we deal with multidomain noninteracting particles.

Main results of magnetic characterization of the examined $\mathrm{Co}(\mathrm{C}), \mathrm{Ni}(\mathrm{C})$ and $\mathrm{Fe}(\mathrm{C})$ samples for two different carbon contents are collected in Table. Magnetization of saturation $M_{\text {sat }}$ is the moment measured at the highest available field $H=56 \mathrm{kOe}$. As expected, magnetic properties of nanocapsules differed from those of the bulk element. Taking known values of saturation magnetization equal to $2.2 \mu_{\mathrm{B}}$ for Fe, $1.7 \mu_{\mathrm{B}}$ for Co and $0.6 \mu_{\mathrm{B}}$ for $\mathrm{Ni}$, one can see that for all samples under study $M_{\text {sat }}$ at $T=4.3 \mathrm{~K}$ is about $30 \%$ smaller than for bulk metal sample. A similar $M_{\text {sat }}$ decrease was observed for Co nanoparticles encapsulated in graphitized carbon shells prepared using the catalytic chemical vapor deposition (CCVD) method [6]. In all cases (see Table) decrease in the saturation moment is a bit stronger for the samples with higher carbon content. It is worth to note that the shape of the $M / M_{\text {sat }}$ vs. $H$ curves was the same for two carbon contents (not shown) in case of all three types of examined nanoparticles. The ratio of remnant to saturation magnetization $M_{\mathrm{REM}} / M_{\text {sat }}$ was largest for $\mathrm{Ni}(\mathrm{C})$ nanocapsules and did not change much for other carbon content for all three types of samples.
TABLE

Summary of properties of examined $\mathrm{Co}(\mathrm{C}), \mathrm{Ni}(\mathrm{C})$ and $\mathrm{Fe}(\mathrm{C})$ samples with different CC.

\begin{tabular}{c|c|c|c|c|c|c}
\hline \hline Sample & $\mathrm{CC}$ & $\begin{array}{c}H_{\mathrm{C}} \\
{[\mathrm{Oe}]}\end{array}$ & $\begin{array}{c}M_{\mathrm{sat}} \\
{[\mathrm{emu} / \mathrm{g}]}\end{array}$ & $\begin{array}{c}M_{\text {sat }}\left[\mu_{\mathrm{B}}\right] \\
\frac{M_{\text {sat }}}{M_{\mathrm{bulk}}}[\%]\end{array}$ & $\begin{array}{c}M_{\mathrm{REM}} \\
{[\mathrm{emu} / \mathrm{g}]}\end{array}$ & $\frac{M_{\mathrm{REM}}}{M_{\mathrm{sat}}}$ \\
\hline $\mathrm{Co} 1$ & $0.058 \frac{\mathrm{g}_{\mathrm{C}}}{\mathrm{g}_{\mathrm{Co}}}$ & 610 & 105.8 & $1.12(64 \%)$ & 15.19 & 0.14 \\
$\mathrm{Co} 3$ & $0.008 \frac{\mathrm{g}_{\mathrm{C}}}{\mathrm{g}_{\mathrm{Co}}}$ & 610 & 115.7 & $1.22(70 \%)$ & 19.78 & 0.17 \\
$\mathrm{Ni} 1$ & $0.114 \frac{\mathrm{g}_{\mathrm{C}}}{\mathrm{g}_{\mathrm{Ni}}}$ & 330 & 40.78 & $0.42(68 \%)$ & 14.1 & 0.35 \\
$\mathrm{Ni} 4$ & $0.041 \frac{\mathrm{g}_{\mathrm{C}}}{\mathrm{g}_{\mathrm{Ni}}}$ & 330 & 45.76 & $0.47(76 \%)$ & 16.6 & 0.36 \\
$\mathrm{Fe} 1$ & $0.109 \frac{\mathrm{g}_{\mathrm{C}}}{\mathrm{g}_{\mathrm{Fe}}}$ & 390 & 155.6 & $1.55(70 \%)$ & 25.03 & 0.15 \\
$\mathrm{Fe} 4$ & $0.037 \frac{\mathrm{g}}{\mathrm{g}_{\mathrm{Fe}}}$ & 390 & 167.5 & $1.68(76 \%)$ & 25.69 & 0.16
\end{tabular}

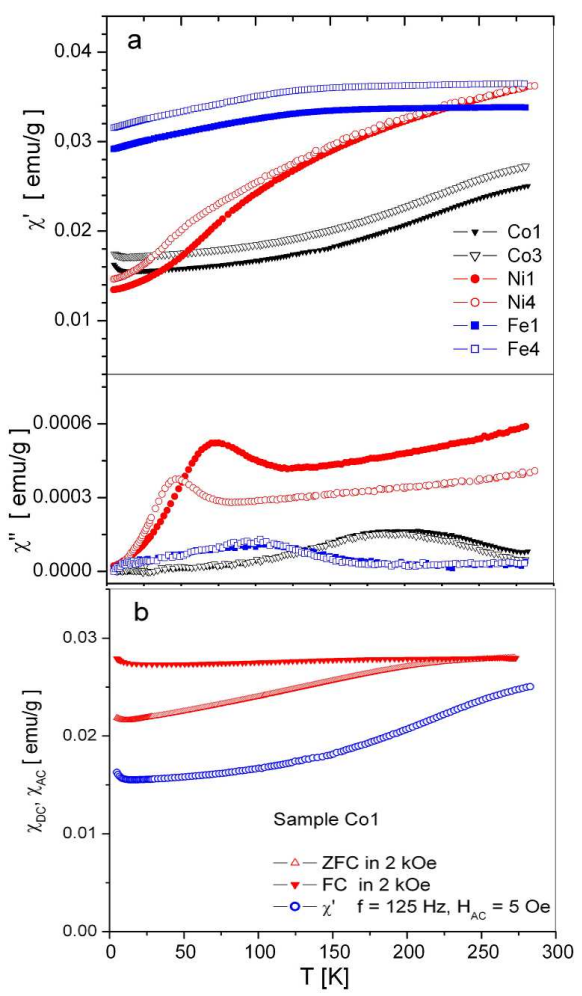

Fig. 4. (a) Temperature dependences of in-phase and out-of-phase AC susceptibility $\left(f=125 \mathrm{~Hz}, H_{\mathrm{AC}}=\right.$ $5 \mathrm{Oe})$ for $\mathrm{Co}(\mathrm{C}), \mathrm{Ni}(\mathrm{C})$ and $\mathrm{Fe}(\mathrm{C})$ nanocapsules with different carbon contents; (b) AC susceptibility as compared to DC susceptibility measured in the ZFC and DC mode for the Co1 sample.

Temperature dependence of the in-phase and out-of-phase AC susceptibility for all examined samples is shown in Fig. 4a. The real component of AC susceptibility as well as DC magnetization vs. temperature dependences obtained in the zero field cooled (ZFC) and field cooled (FC) mode for $\mathrm{Co}(\mathrm{C})$ sample is given in Fig. 4b. Presented results indicate a very high average blocking temperature $\left(T_{\mathrm{B}}>300 \mathrm{~K}\right)$. The shape of the $\chi_{\mathrm{AC}}(T)$ curve reflects the distribution of blocking temperatures resulting from the wide size distribution of ex- 
amined particles. We can also note that AC susceptibility is stronger for samples with smaller $\mathrm{CC}$, which is consistent with DC measurements. The susceptibility rise (see Fig. 4b) observed on cooling in the lowest temperature range for $\mathrm{Co}(\mathrm{C})$ particles is related to the small content of the $\mathrm{Co}_{3} \mathrm{O}_{4}$ phase, documented also with X-ray measurements.

\section{Conclusions}

Carbon-coated cobalt, nickel, and iron nanocapsules were successfully synthesized by means of carburization with methane. The XRD results showed that examined samples contained chosen metals, in case of Co particles fcc-Co and bcc-Co phases were detected. As seen from TEM images, the graphite-like coated particles formed agglomerates of the relatively large size. Saturation of magnetization was dependent on carbon content: larger CC caused smaller saturation moment. Coercivity field and ability of magnetization for particular types of samples were independent of CC. Shapes of the $\chi_{\mathrm{AC}}(T)$ curves indicated the wide size distribution of par- ticles. No superparamagnetic behavior at room temperature was observed; blocking temperature for all samples was above room temperature.

\section{References}

[1] Z.D. Zhang, J. Mater. Sci. Technol. 23, 1 (2007); www.jmst.org/pcn/qikan/manage/wenzhang/ 2006331.pdf.

[2] E.M. Brunsman, R. Sutton, E. Bortz, S. Kirkpatrick, K. Midelfort, J. Williams, P. Smith, M.E. McHenry, S.A. Majetich, J.O. Artman, M. De Graef, S.W. Staley, J. Appl. Phys. 75, 5882 (1994).

[3] X.L. Dong, Z.D. Zhang, Y.C. Chuang, S.R. Jin, Phys. Rev. B 60, 3017 (1999).

[4] U. Narkiewicz, M. Podsiadły, W. Arabczyk, M.J. Woźniak, K.J. Kurzydłowski, Mater. Sci. Eng. C 27, 1273 (2007).

[5] Ullmann's Encyclopedia of Industrial Chemistry, 6th ed., CD-ROM version, 2004.

[6] E. Flahaut, F. Agnoli, J. Sloan, C. O'Connor, M.L.H. Green, Chem. Mater. 14, 2553 (2002). 